\title{
ESTIMATION OF BENEFITS FROM THE ACTUAL USE OF INLAND WATER ECOSYSTEM SERVICES IN THE SLOVAK REPUBLIC
}

\section{RADOSLAV BUJNOVSKÝ}

Water Research Institute, Nábr. arm. gen. L. Svobodu 5, 81249 Bratislava, Slovak Republic; e-mail: radoslav. bujnovsky@vuvh.sk

\begin{abstract}
Bujnovský R.: Estimation of benefits from the actual use of inland water ecosystem services in the Slovak Republic. Ekológia (Bratislava), Vol. 37, No. 3, p. 201-218, 2018.

The primary aim of the article is to obtain an overview of benefits from the actual use of inland water ecosystem services (ESSs) in Slovakia. The evaluation, which includes both surface water and groundwater, is primarily focused on demand side. Methods for assessing the benefits of the most prevalent ESSs, designated by Common International Classification of Ecosystem Services (CICES classification) v. 4.3, are described and discussed. The evaluation is performed at the level of 10 sub-basins to which available data are allocated. In the absence of necessary data or the impossibility of allocating them to sub-basins, the benefit from the use of some ESSs is estimated at the level of whole Slovak territory. The use of ESSs valuation in practice, especially with regard to water protection of surface water and groundwater, is discussed. The evaluation of benefits from ESSs of inland waters in Slovakia so far does not allow direct use of obtained results for proposal of measures within river basin management plans as suggested by several authors. Main reason is the input data availability and quality. At the present time, the significance of the ESSs evaluation may rather lie in the awareness of the value that human society gains from the use of inland waters. It becomes more evident that increase in environmental awareness alone is not sufficient in terms of the protection of ecosystems and their services. To achieve unambiguous and lasting improvement in this area, it is necessary to address the deeper causes, closely related to human thinking and behaviour.
\end{abstract}

Key words: inland waters, surface waters, groundwater, ecosystem services, evaluation methods, benefits.

\section{Introduction}

In the past decades, the concept of ecosystem services (ESSs) has been the subject of great attention, which confirms the wide range of publications related to different types of ecosystems - their mapping, evaluation and use or protection (e.g. Farber et al., 2006; Boyd, Banzhaf, 2007; DeGroot et al., 2010; Maes et al., 2011; Burkhard et al., 2012; DeGroot et al., 2012; COWI, 2014b; Schröter et al., 2014; Grizzetti et al., 2015a; Seifert-Dähnn et al., 2015; Maes et al., 2016).

ESSs represent the outputs of natural systems from which people have or may have benefits. The importance of water as a natural resource and aquatic ecosystems for human society 
$\mathrm{T} \mathrm{a} \mathrm{b} \mathrm{l} \mathrm{e} \mathrm{1.} \mathrm{Significant} \mathrm{ecosystem} \mathrm{services} \mathrm{of} \mathrm{inland} \mathrm{waters} \mathrm{and} \mathrm{related} \mathrm{benefits} \mathrm{from} \mathrm{their} \mathrm{provision} \mathrm{in} \mathrm{Slovak} \mathrm{conditions}$ (Bujnovský, 2015 - revised).

\begin{tabular}{|c|c|c|}
\hline \multicolumn{2}{|r|}{ Ecosystem services } & Benefits from ESSs \\
\hline \multicolumn{3}{|c|}{ Surface water } \\
\hline \multirow[t]{4}{*}{ Provisional } & Biomass form aquaculture & Water animals - namely, fishes \\
\hline & Raw water & $\begin{array}{l}\text { Water for drinking purposes, } \\
\text { Water for crop irrigation, } \\
\text { Water as raw material and cooling } \\
\text { medium in industry }\end{array}$ \\
\hline & $\begin{array}{l}\text { Materials (the consequence of } \\
\text { substances accumulation) }\end{array}$ & $\begin{array}{l}\text { Gravel, sands (possibly riverbed } \\
\text { sediments) }\end{array}$ \\
\hline & Renewable energy & Electricity production \\
\hline \multirow{3}{*}{$\begin{array}{l}\text { Regulation and } \\
\text { maintenance }\end{array}$} & Regulation of water quality & Nitrogen retention \\
\hline & Transportation medium & Ship transportation on Danube River \\
\hline & Habitat preservation, biodiversity & $\begin{array}{l}\text { Creation of conditions for aquatic } \\
\text { biotopes }\end{array}$ \\
\hline \multirow[t]{2}{*}{ Cultural } & $\begin{array}{l}\text { Physical interaction with inland } \\
\text { water ecosystems }\end{array}$ & $\begin{array}{l}\text { Recreational activities (recreational } \\
\text { fishing, bathing, water tourisms) }\end{array}$ \\
\hline & $\begin{array}{l}\text { Intellectual, symbolic and } \\
\text { spiritual interactions with } \\
\text { ecosystems }\end{array}$ & $\begin{array}{l}\text { Object of research and education, } \\
\text { relaxing, national identity and cultural } \\
\text { heritage }\end{array}$ \\
\hline \multicolumn{3}{|c|}{ Groundwater } \\
\hline \multirow[t]{2}{*}{ Provisional } & Raw water & $\begin{array}{l}\text { Water for drinking purposes, } \\
\text { Water for crop irrigation, } \\
\text { Water as raw material and cooling } \\
\text { medium in industry }\end{array}$ \\
\hline & Renewable energy & Source of geothermal energy \\
\hline $\begin{array}{l}\text { Regulation and } \\
\text { maintenance }\end{array}$ & Habitat preservation, biodiversity & $\begin{array}{l}\text { Creation of conditions for water } \\
\text { influenced (especially terrestrial) } \\
\text { biotopes }\end{array}$ \\
\hline Cultural & $\begin{array}{l}\text { Physical interaction with inland } \\
\text { water ecosystems }\end{array}$ & $\begin{array}{l}\text { Recreational activities on exposed } \\
\text { groundwater (fishing, bathing) }\end{array}$ \\
\hline
\end{tabular}

results from the provision of a whole range of functions and subsequently ESSs that meet human needs, either directly or indirectly. Relevant types of benefits from these ESSs are indicated in Table 1. As stated by Schröter et al. (2014), the concept of ESSs is primarily anthropocentric, giving rise to a considerable wave of criticism as well as advocacy of the concept.

Owing to declining of ecological life-support systems in consequence of anthropogenic pressures, as pointed in many documents and papers (e.g. Millennium Assessment, 2005; EEA, 2015), there arises the need of effective protection of environment, biota inclusive. 
Improving management and preventing overexploitation of natural resources, together with the value of ESSs, is one of the objectives of the renewed EU Sustainable Development Strategy. The assessment of ESSs is also enshrined in the EU Biodiversity Strategy by 2020. Achieving Goal 4 of the EU Biodiversity Strategy 2020 corresponds to a certain extent with the assessment of ecosystem services linked to inland waters (rivers and lakes).

Understanding, mapping and evaluation of benefits from ecosystem and biodiversity is considered to be the first step to enhance their protection (Maes et al., 2011) especially if they had been integrated into the relevant policies. One of these policies is also water policy, incorporated in the Water Framework Directive, and corresponds with inland waters.

There are two aspects of the evaluation of ecosystem services, namely, the supply and demand, which together determine their value (Austin et al., 2012). Even though there may be discrepancies between supply and demand parts (Burkhard et al., 2012), the actual water use (which can be considered as a proxy of demand) is easily identifiable and the relevant data can be more accessible.

\section{Material and methods}

The evaluation of ESSs of inland waters, which includes both surface water and groundwater (where relevant), is based on CICES v. 4.3 classification (Haines-Young, Potschin, 2013) and primarily focused on demand side, which indicates their actual use (see Table 1). The evaluation of ESSs, which consists of quantifying of given ESS in biophysical terms and selection of an appropriate economic valuation tool, is mainly based on relevant documents (COWI, 2014a,b; Grizzetti et al., 2015a,b) and more is described and discussed in next part. The assessment of water use suitability for a particular purpose (representing a specific ESS) is based on the assumption that the water quality complies with the relevant requirements what is actual especially for raw water for drinking purposes, water for crop irrigation, recreational fishing, bathing as well as for biomass - water animals, habitat preservation and biodiversity.

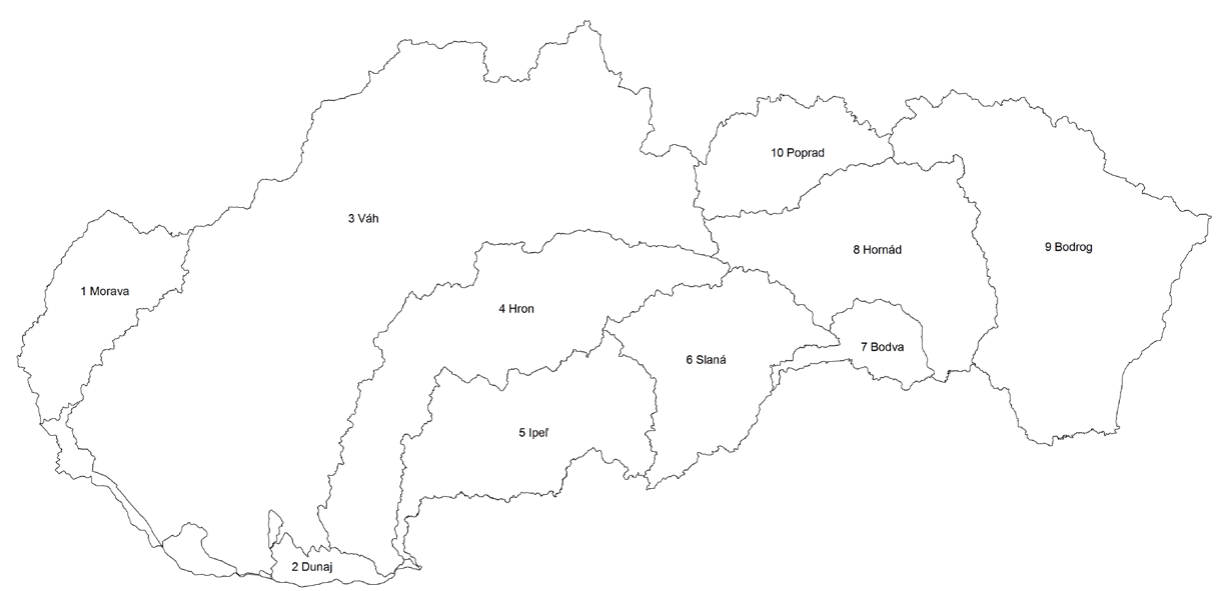

Fig. 1. Definition of sub-basins in Slovakia. 
The evaluation is performed at the level of 10 sub-basins of Slovakia (see Fig. 1), to which available data (related to consumption or utilisation of water, fish catches or number of visitors) are allocated. It concerns the following ESSs:

- provision of raw water for drinking purposes,

- provision of water for crop irrigation,

- $\quad$ provision of gravel and sand,

- $\quad$ provision of renewable energy (water as medium for electricity production),

- transportation medium - ship transportation on the Danube River (relevant just for one sub-basin),

- $\quad$ physical interaction with inland water ecosystems - recreational fishing,

- $\quad$ physical interaction with inland water ecosystems - bathing.

In the absence of data, the benefit from the use of some ESSs is estimated at the level of whole territory of Slovakia and concerns the following ESSs:

- $\quad$ provision of biomass - water animals, namely, fishes from aquaculture,

- $\quad$ provision of water as raw material and cooling medium in industry (except energetic industry),

- regulation of water quality - nitrogen retention in surface waters,

- habitat preservation and biodiversity,

- $\quad$ intellectual, symbolic and spiritual interactions with inland water ecosystems.

The primary aim of the article is to obtain an overview of benefits from inland water ESSs used in Slovakia, which are expressed by monetary values. This is preceded by the choice of economic assessment methods and the corresponding biophysical assessment. As detecting the preferences of people and their willingness to pay for ESSs is in many cases burdened with insufficient awareness of real meaning of functions and services provided by ecosystem (e.g. Chee, 2004; Brouwer, 2008), for economic evaluation of most ESSs, non-preferential methods are used. As indicated by several articles, these methods are suitable for economic valuation of benefits from the production and regulation of ESSs (COWI, 2014a,b; Rohani, 2013; Grizzetti et al., 2016).

\section{Results and discussion}

\section{Provision of biomass - water animals, namely, fishes from aquaculture}

This ecosystem service corresponds to fish farming in watercourses and reservoirs and basically represents a purposeful anthropic regulation of the populations of selected fish species and their breeding. According to COWI $(2014 \mathrm{a}, \mathrm{b})$, this ESS includes not only fish farming but also recreational fishing. In this article, recreational fishing is classified as cultural service. Estimate of the benefit from the use of this EES presupposes the availability of information on the annual production of individual fish species and their market valuation, which corresponds with approach published in COWI (2014a,b) and Grizzetti et al. (2015a).

Owing to restricted data availability, valuation of referred ESS is performed via estimation of benefit based on annual production of lowland and trout species in 2011, undertaken from National Strategic Plan for the Development of Aquaculture in Slovak Republic in the period 2014-2020 (MoA \& RD, 2013), and their market valuation is estimated from the Slovak Fishing Association price list (5 and $12 € / \mathrm{kg}$ of lowland and trout fish production). Indicative value of catch is subsequently reduced by the cost of artificial restocking. The benefit from the use of this ESS can be around 4 million $€$. As the effect of negative externalities is not taken into account, this value can be considered as overestimated.

\section{Provision of raw water for drinking purposes}

Estimating the benefit from the use of this ESS basically lies in an expression of the economic value of raw water, which depends mainly on the sufficiency of exploitable water in the water source and its quality (Elsin et al., 2010; Morris, Camino, 2011; NCGRT, 2013). 
Valuation of specified ESS, performed at sub-basins level, is based on the amount of abstracted surface or ground water (data obtained from Slovak Hydrometeorological Institute) and the use of regulated market prices, which corresponds with recommended procedures (COWI, 2014a,b). Abstracted water, treated subsequently for drinking purposes, is provisionally priced in terms of price decision of the Regulatory Office for Network Industries (ÚRSO) for the Slovak Water Management Enterprise (state company) as average for the period 2011$2013\left(0.1101 € \mathrm{~m}^{-3}\right)$. The same price is used for both surface water and groundwater, despite the fact that price for groundwater abstraction is three times lower in comparison to surface water. Mentioned unit price in Slovak conditions can be regarded as reasonable and comparable with abroad (Morris, Camino, 2011). The benefit from the use of this ESS, based on the mentioned approach, represents 33 million $€$. The relative share of individual sub-basins on the total benefit from this ESS as well as the benefit per $1 \mathrm{~km}^{2}$ or 1000 inhabitants of given sub-basin for this ESS are illustrated in Fig. 2. The adjustment of water withdrawal prices (so far in the 5-year cycle) in the sense of the regulatory policy of the URSO will be projected into a gradual increase into benefits from the use of this ESS with an assumption that water abstraction will not decrease.

\section{Provision of water for crop irrigation}

The increase in yield because of irrigation can be considered as the effect of the current use of this ESS, which depends on the availability of irrigation systems, the structure/types of crops grown and, last but not least, the economic prosperity of farms. In general, it is possible to state that the potential of water use (in Slovakia mainly surface) for irrigation is higher than the recorded water consumption for this purpose in the past 20-25 years.

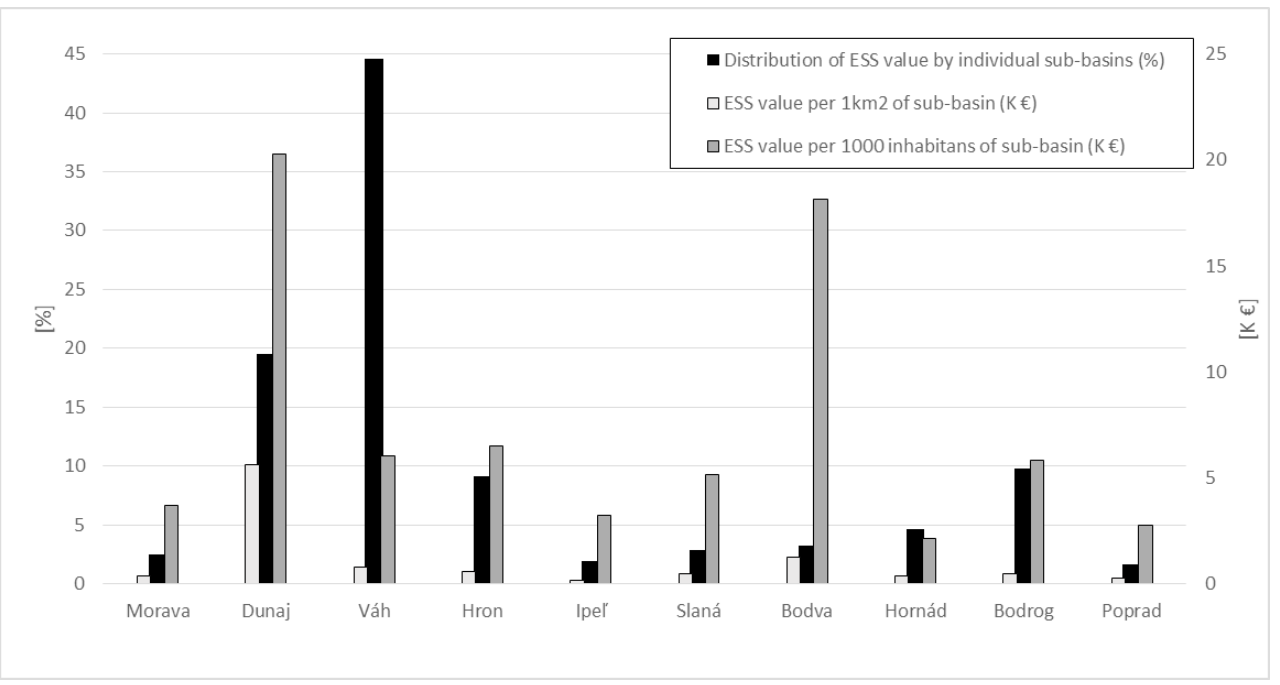

Fig. 2. Expression of the benefit from ESS 'provision of raw water for drinking Purposes' at sub-basin level. 
The valuation of the given ESS, performed at sub-basin level, is based on the average amount of abstracted surface water and groundwater in the period 2011-2013 (data obtained from Slovak Hydrometeorological Institute) reduced by non-productive evaporation. Increment of dry matter plant biomass (estimated from the amount of consumed water and selected value of transpiration coefficient equal to $600 \mathrm{~kg}$ of water for creating of $1 \mathrm{~kg}$ of dry matter) is provisionally expressed by early potatoes. Average market price of this commodity during the period 2011-2013 is used to measure the effect (application of production principle). The market valuation method used corresponds with recommended approaches (COWI, 2014a,b; Grizzetti et al., 2015a).

Rental costs of irrigation and operational units as well as electricity costs associated with pumping and transport of water to lands subsequently were deducted from the economic value. This approach corresponds with the recommendation of Ward and Michelsen (2002) to separate transport costs from the cost of raw material. The benefit from the use of this ESS, based on the mentioned approach, is 25 million $€$. The relative share of individual sub-basins on total benefit from this ESS as well as benefit per $1 \mathrm{~km}^{2}$ or 1000 inhabitants of given subbasin for this ESS are illustrated in Fig. 3.

As mentioned previously, the demand capacity of the given ESS is determined by economic prosperity of farms and farming profitability. Although, during the period 2005-2016, farmers did not have to pay for the abstraction of irrigation water, its consumption did not rise, which indicates a low demand for elasticity primarily caused by high energy demand of existing irrigation systems. It is possible to assume that the irrigation water consumption in the near future should not increase significantly, also because of the gradual increase in the efficiency of irrigation systems (they often need reconstruction) as well as in terms of their cost-effective use oriented to cash crops.

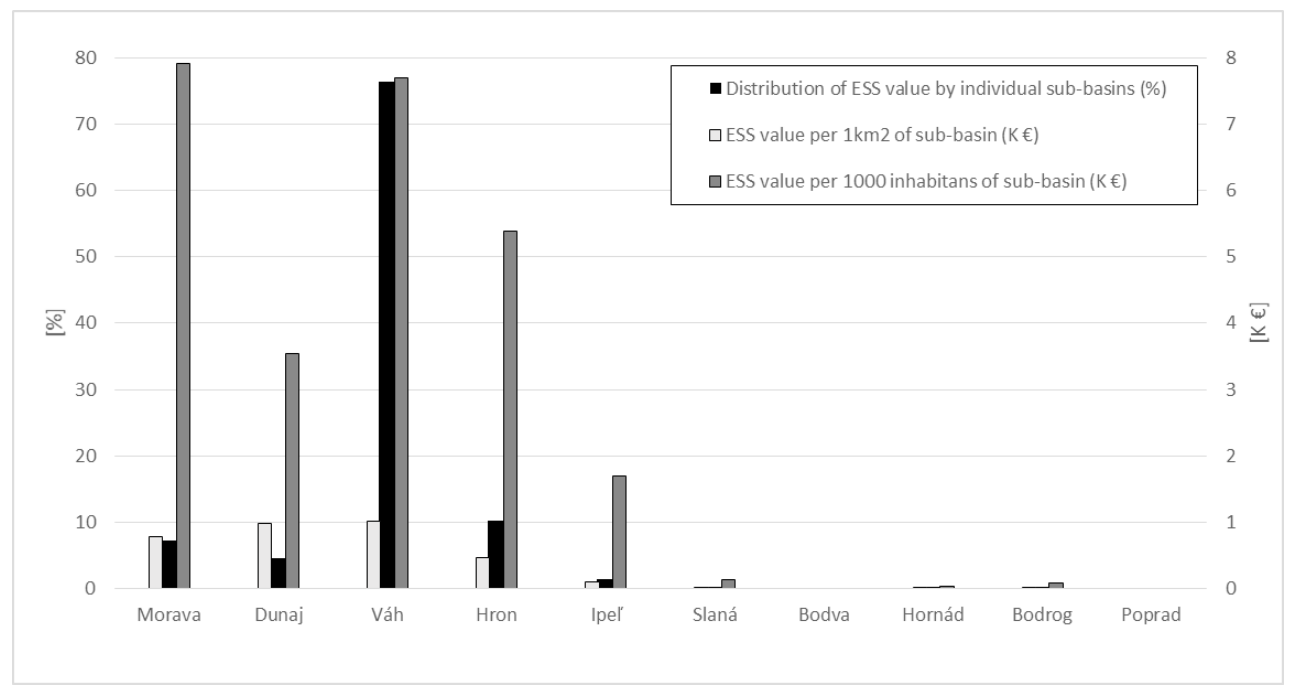

Fig. 3. Expression of the benefit from ESS 'provision of water for crop irrigation' atsub-basin level. 
Referred ESS can be assessed based on the data on water abstraction for the given purpose (data obtained from Slovak Hydrometeorological Institute), either through production or market valuation approach (COWI, 2014a,b). In the absence of information related to added value of water used in various industrial sectors (food industry, chemical industry, steel industry, etc.), the production principle is difficult to apply. Moreover, water can also be used for cooling (consumption of water in energetic industry is a separate problem that is not addressed here). For this reason, the benefit from this ESS could be roughly estimated only at national level using the indirect comparative approach. Assuming that the benefit from unit amount of abstracted water would be (preliminary) the same as from water used for crop irrigation, the benefit from the given ESS could be around 278 million $€$.

Nevertheless, similarly, for the estimation of resource costs within the meaning of Water Framework Directive (WFD) Article 9, in case of this ESS, the greatest benefit per unit of abstracted water can be expected. Thus the price of water supply for industrial use, recommended by COWI $(2014 a$, b) for pricing of water used in industry, will underestimate the benefit from this ESS. It is necessary to mention that the use of this ESS is not always linked to achievement or failure to achieve good ecological and chemical status of water. On the other hand, overexploitation of water (especially the surface one) can negatively affect the ecological status of affected waters because industry together with cities and municipalities belong to sectors with major share on water abstraction in Slovakia.

\section{Provision of gravel and sand}

This abiotic ESS, designated by COWI (2014a,b) as geological sources, is based on the removal and subsequent accumulation of water-borne substances (gravel, sand or riverbed sediments) initiated by the need to remove them for the provision of shipping (maintenance of the Danube waterway) or the need for maintenance of river beds - which is part of the binding activities of the administrator of watercourses Slovak Water Management Enterprise (SVP š.p.). Provision of this ESS is not linked to achievement or failure to achieve good ecological and chemical status of water or some water quality parameters.

For the valuation of specified ESS, performed at the sub-basin, the cost method based on pricing of extracted gravel/sand is used. The data were received from watercourse administrator - SVP š.p. The effect of negative externalities (effect on life and reproduction of aquatic animals, especially fish) is not taken into account. In comparison with the previous ESS, the benefit from the use of this ESS is the smallest amongst all evaluated ones ( 0.6 million $€$ ). The relative share of individual sub-basins on total benefit from this ESS as well as benefit per $1 \mathrm{~km}^{2}$ or 1000 inhabitants of given sub-basin for this ESS are illustrated in Fig. 4. After considering the negative externalities, related to the worsening of breeding and living conditions of fish species, mentioned benefit can be even lower. This negative effect is difficult to quantify, amongst other things, because in numerous fishing grounds, the fish population is regulated by man.

The riverbed sediments resulting from the surface water purification process are generally recommended to be used for the improvement of soil properties (Gunkel et al., 2015). 
Their practical use is limited because the content of pollutants that are bound to the organic or inorganic fraction of these sediments usually prevents their application to agricultural land. So riverbed sediments are not included into the evaluation of this ESS.

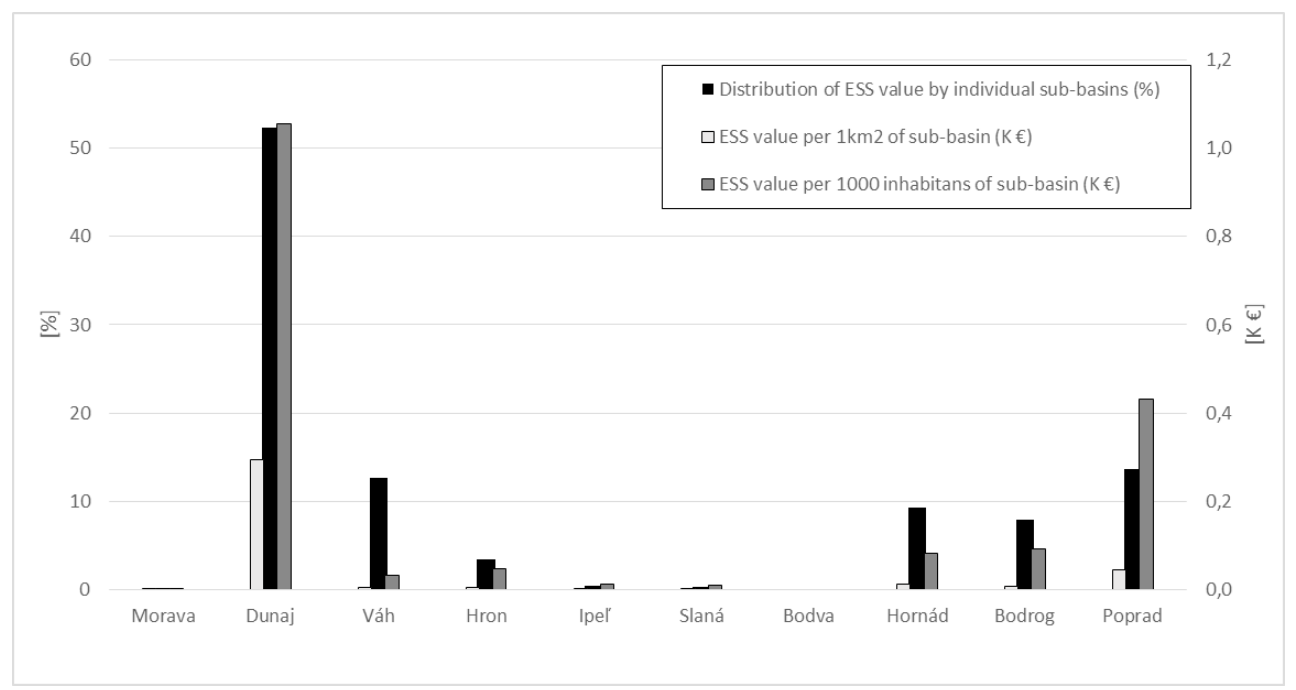

Fig. 4. Expression of the benefit from ESS 'provision of gravel and sand' at sub-basin level.

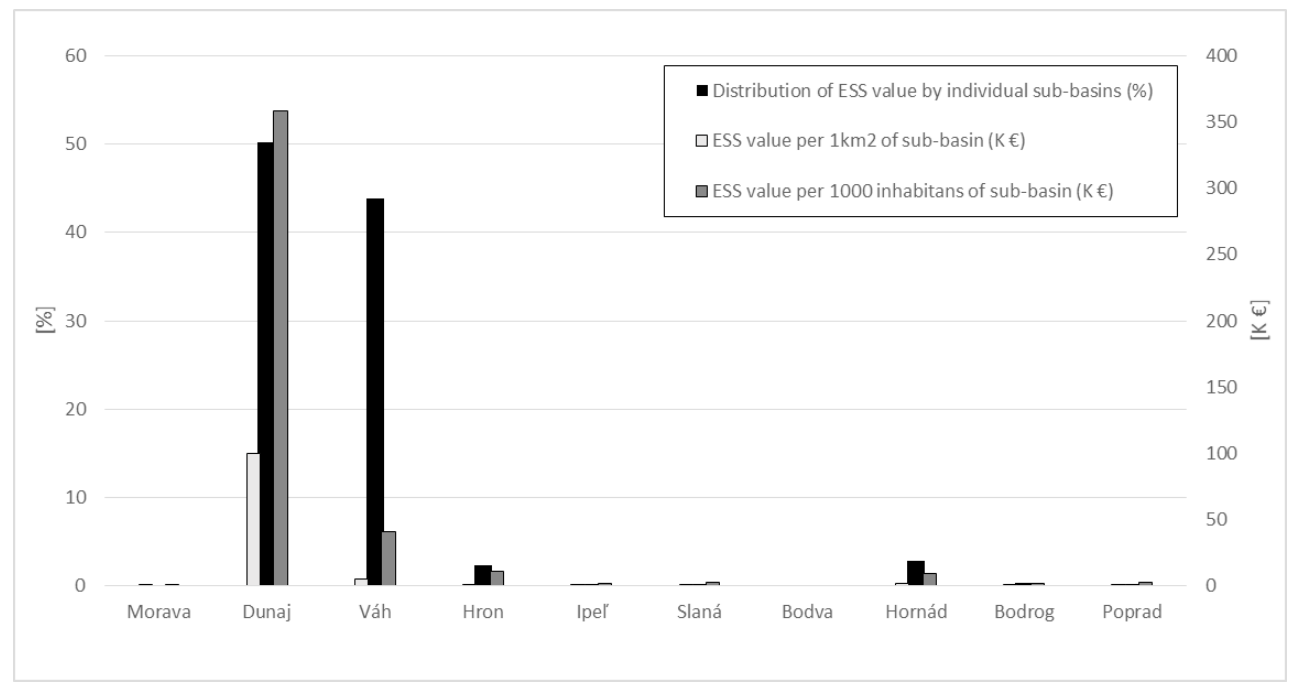

Fig. 5. Expression of the benefit from ESS 'provision of renewable energy (electricity production)' at sub-basin level. 
This abiotic ESS corresponds with the use of hydropower potential of surface waters for electricity production. The use of specified ESS is not linked to achieving or failing to achieve good ecological and chemical status of the water or some water quality parameters.

The basic prerequisite for obtaining the benefits from this type of water use is the construction of water reservoirs and installation of devices for the production of electricity. The estimation of benefit is based on the technical hydro-energetic potential of water courses on built and used hydroelectric power plants (MoE, 2011). Considered summary annual power of these plants is converted to the average wholesale electricity price in 2012.

The assessment of given ESS, performed at sub-basin level, is in line with recommended methods (COWI, 2014a,b; Grizzetti et al., 2015a), and the corresponding benefit is possible to express by market value of electricity. The benefit from the use of this ESS represents 229 million $€$. The relative share of individual sub-basins on the total benefit from this ESS as well as benefit per $1 \mathrm{~km}^{2}$ or 1000 inhabitants of given sub-basin for this ESS are illustrated in Fig. 5. After considering the negative externalities, the benefit can be lower. As introduced in World Water Assessment Programme document (WWAP, 2014), generation of electricity in hydropower plants is linked to the use of water dams that cause fragmentation of river systems and adversely affect river ecology with impact on living conditions and reproduction of aquatic species, biodiversity and water quality. On the other side, dams and reservoirs may have a multi-purpose use (reduction/elimination of seasonal flooding, crop irrigation, recreation, water purification via sedimentation not excluding).

Measuring the difference in the cost of electricity generation compared to the cost of an alternative production method of production (taking into account externalities) is admittedly more objective and can provide clearly lower ESS value when the necessary data are available.

\section{Transportation medium - ship transportation on the Danube River}

Shipping belongs to the main types of water use and simultaneously (by COWI, 2014a,b) to the abiotic ecosystem services. The use of given ESS is not related to achieving or failing to achieve good ecological and chemical status of the water or some water quality parameters. The valuation of specified ESS, relevant mainly for Slovak part of the Danube, is consistent with the COWI approach (COWI, 2014a, b). The benefit estimation is based on the comparison of ship transportation with the nearest transport alternative (rail), which corresponds to the substitution method. The difference between the transport costs of shipping on the Slovak part of the Danube (estimated and provided by Slovak Cruises and Harbors, J.S.C.) and transport costs through transit rail transport at the same distance (taken from the price list of Cargo Slovakia, J.S.C. - the average for the period 2011-2013) and deducting maintenance costs for the waterway represents 67 million $€$ per year in favour of shipping. Negative externalities from the use this ESS are not taken into account. 
This ESS, to some extent, corresponds to the cleaning (and subsequently discharge) of waste water. Discharge of waste waters and pollutants contained therein, regulated by permits, is usually based on the principle of dilution. Both terrestrial (ex-situ) and aquatic ecosystems (in situ) are involved in surface water cleaning. Retention (reduction) of nitrogen content in aquatic ecosystems (rivers, streams, lakes) is attributed to nitrogen assimilation by suspended and benthic algae, nitrogen intake by macrophytes (which actually corresponds to the retention or accumulation) and denitrification, which, in contrary to uptake of this nutrient by the biotic component, contributes to permanent removal of nitrogen from the aquatic environment (e.g. Wollheim et al., 2006; Rode et al., 2015). Europe's nitrogen retention represents several percentage of the nutrient inputs into surface water. Therefore, in many cases, provision of mentioned ESS is only a contributory factor for nitrogen reduction in the aquatic environment that does not guarantee the achievement of good ecological status (ES) of water in terms of this nutrient/ substance, as evidenced by the information of Maes et al. (2011) and Grizzetti et al. (2015b).

Owing to the unavailability of data, only a rough estimate of relevant benefit on the level of Slovakia is performed. The evaluation of this ESS is in line with the indicator nitrogen retention or the amount of removed pollutant specified in several documents (COWI, 2014a,b; Grizzetti et al., 2015a,b). The valuation of the ESS in question by the substitution method corresponds to the estimated costs of alternative ways to reduce this nutrient in the aquatic environment, which are either the costs of wetland constructing or the costs of floodplains restoration (e.g. Grossmann, 2012; La Note et al., 2012).

At the selected nitrogen retention rate of $4 \mathrm{~kg} \mathrm{~N} \cdot \mathrm{ha}^{-1}$ per year (estimated based on data by Seitzinger et al., 2006) in the river network and in the reservoirs, the economic value (benefit) of this ESS is preliminarily estimated at 3 million $€$.

\section{Habitat preservation and biodiversity}

This ESS does not have a direct link to securing the main types of water use (e.g. drinking water supply, collection and treatment of wastewater, water use in industry, water use in agriculture, water transport, fisheries), but it can be affected by them. Achieving good ecological and chemical status of water (postulated by EU Water Framework Directive) is one of the preconditions for ensuring the protection of (natural and affected) habitats. Estimating the benefit from the use of this ESS is currently problematic. From economic methods, as stated in COWI $(2014 \mathrm{a}, \mathrm{b})$, the preference method of 'willingness to pay' is recommended in this case. As indicated by Chee (2004), the results obtained by preference methods can be greatly distorted because of the lack of awareness/knowledge of respondents on real significance of the function(s) and consequently of the ecosystem. Another possibility is to use expert methods (Seják et al., 2010) in which setting the value (related to one point) is based on the costs of already implemented revitalisation measures.

Owing to the unavailability of necessary data, only a rough estimate of relevant benefit from surface waters on the level of Slovakia is performed. It is assumed that the conditions for fish life (which are at the top of the food chain in aquatic ecosystems - regardless of 
aquatic birds and some mammals living in the aquatic environment) and then their populations reflect environmental conditions and biodiversity. The annual cost of restocking fishing grounds (undertaken from Slovak Fishing Association) are used for the estimation of the given ESS benefit, which is about 5 million $€$ per year.

\section{Physical interaction with inland water ecosystems - recreational fishing}

The use of this ESS, which belongs to provisional services, is linked to fishing grounds. Within both surface water and underground water, currently in Slovakia, nearly 1200 fishing grounds is defined, of which the vast majority is administered by the Slovak Fishery Union.

The valuation of specified ESS, performed at sub-basin for surface water and groundwater in 2012, is based on the catch of concrete species and their valuation based on the pricelist of the Slovak Fishery Union with the deduction of the restocking cost. This approach corresponds with now recommended methods so far (COWI, 2014a, b; Grizzetti et al., 2015a). The effect of negative externalities is not taken into account. The benefit from the use of this ESS, calculated based on the mentioned approach, is 3 million $€$. The relative share of individual sub-basins on total benefit from this ESS as well as benefit per $1 \mathrm{~km}^{2}$ or 1000 inhabitants of given sub-basin for this ESS are illustrated in Fig. 6.

Owing to the fact that the fish populations are usually purposefully influenced and targeted in the fisheries areas of the Slovak Republic (artificial restocking, feeding of fishes), the information regarding the benefits from the use of this ESS in the form of catches is overestimated, not giving an objective picture of the potential of the natural environment in this respect.

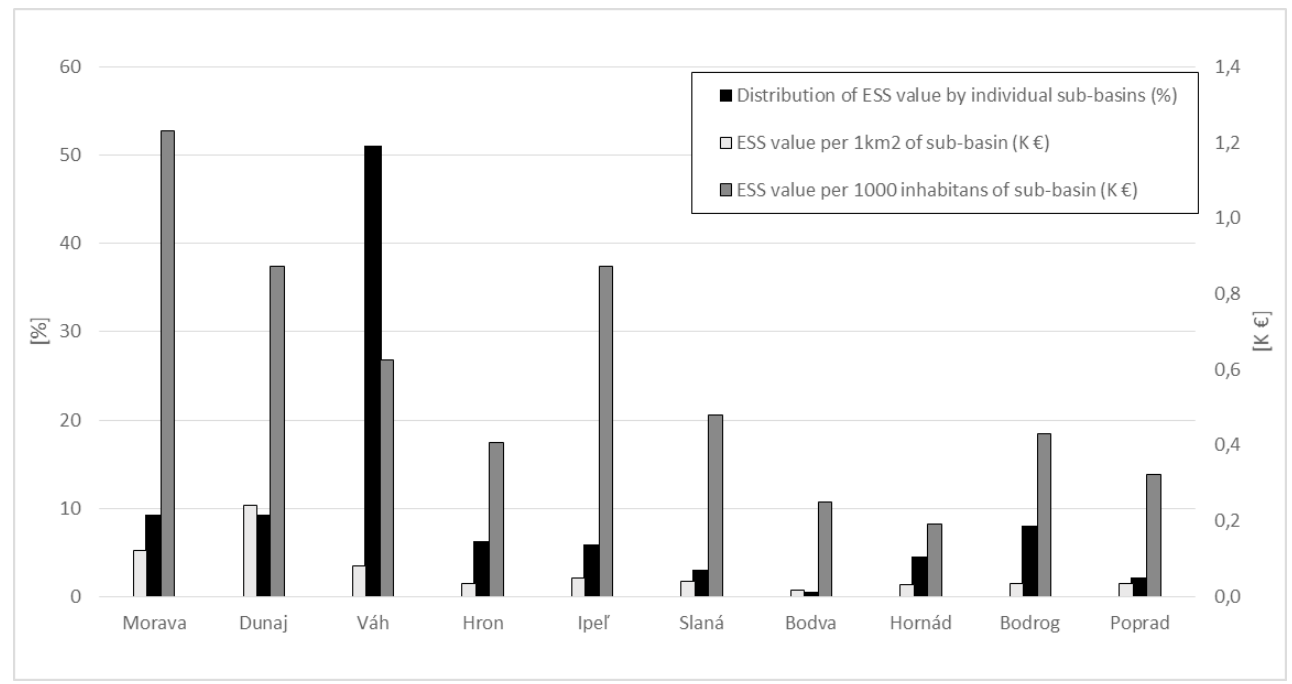

Fig. 6. Expression of the benefit from ESS 'physical interaction with inland water ecosystems - recreational fishing' at sub-basin level. 
Some natural water areas (water reservoirs and exposed groundwater) are used for bathing and recreation. These water areas are defined by national legislation (Act. No 355/2007 Coll.). The list of waters/locations suitable for bathing is updated annually with respect to the results of the particular monitoring performed by national Public Health Authority.

For the valuation of referred ESS, performed at the level of sub-basins for surface water and groundwater in 2011-2013, usually the preferential methods (e.g. travel cost method or derived from visitor incomes to recreational sites - factor income of the area of recreation) are often recommended (COWI, 2014a,b; Grizzetti et al., 2015a). Fees for the use of natural swimming pools (entrance fee) represent another way to estimate the benefit what corresponds with market valuation method. However, it should be noted that the crucial item of the entrance fee (in the case so-called 'operated natural pools') are services provided by the operator and not by natural water pool. In the case of remaining natural bathing waters, approved by national legislation, we can consider only a rough estimate of the potential fees because access and subsequent use of water pool is free.

Another alternative for recreationists is the use of artificial pools whilst bathing water (except for the thermal pools) is often taken from the public water supply systems. Cost savings for water and sewerage (substitution method) represent the immediate benefit of the use of natural waters, which represents approximately 1 million $€$. The relative share of individual sub-basins on total benefit from this ESS as well as benefit per $1 \mathrm{~km}^{2}$ or 1000 inhabitants of given sub-basin for this ESS are illustrated in Fig. 7.

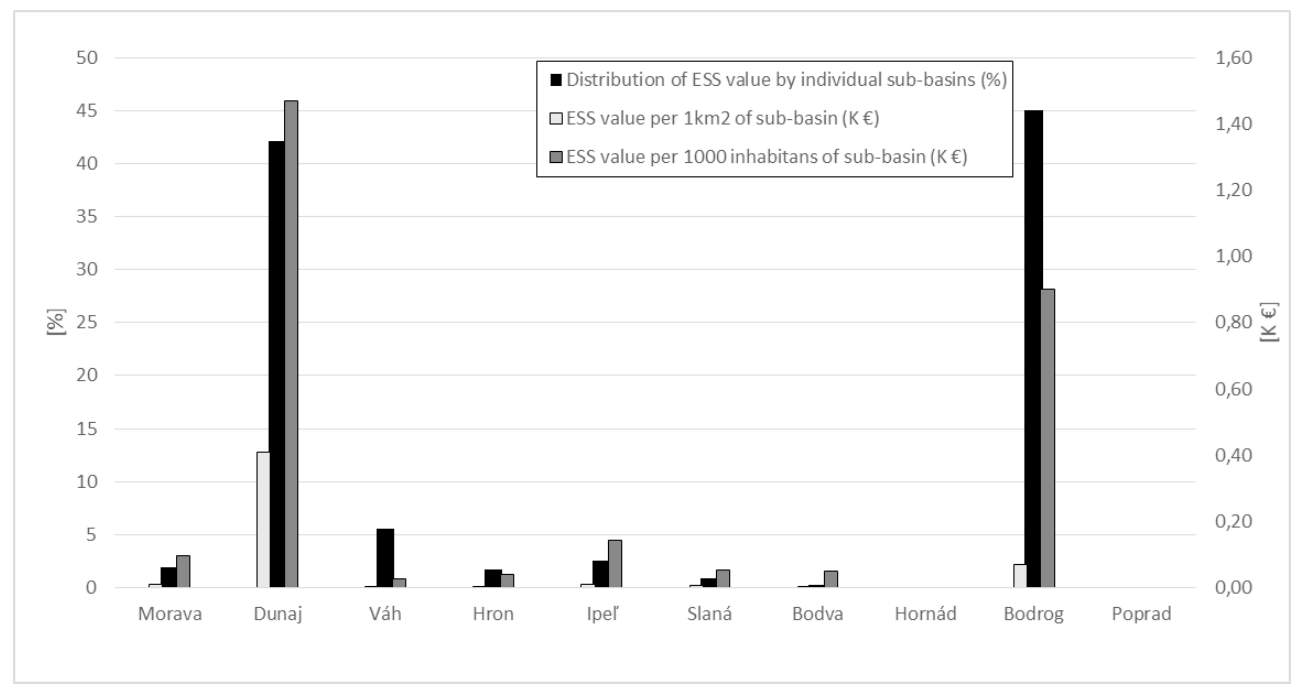

Fig. 7. Expression of the benefit from ESS 'physical interaction with inland water ecosystems - bathing' at sub-basin level. 
For the evaluation of specified ESS, the preferential methods (e.g. willingness to pay) are recommended (e.g. Grizzetti et al., 2015a). In essence, these methods provide a hypothetical benefit value of the ESS in question. As mentioned earlier, people and their willingness to pay for ecosystem services are in many cases burdened with a lack of real meaning of services that given water ecosystem provides. Moreover, potential and even real payment undoubtedly depends on socio-economic factors or living standard of the population. With respect to the long-term decline in the purchasing power of the population or decline in household consumption, which is amongst the lowest in the European Union (Morvay et al., 2014), it can be expected that the benefit from this ESS, related to surface water, will be rather symbolic (estimated less than $1 \%$ of total benefit from all evaluated inland water ESS or comparable to benefit from physical interaction with inland water ecosystems).

As stated by Cooper et al. (2016), people have the benefits of their aesthetic and spiritual experiences in nature. Aesthetic and spiritual values do not have the character of individual preferences and are often socially shared values. They are also not primarily instrumental (in terms of the benefits of an individual or group), but they are constitutive and relational. As a result, it is not about a service of nature for man, but it is about forming a responsible relationship of man to nature.

\section{Some remarks to evaluation of inland water ecosystem services}

There is necessary to distinguish between the methods of evaluation and the goals that correspond with driving forces and pressures related to environmental damage. The trajectory can be described as damaged environment $\rightarrow$ mapping the state and evaluation of benefits (or lost benefits) from ESSs (in this case inland water ecosystems) $\rightarrow$ implementation of measures under the relevant policies that can return the affected environment to desired state.

Data availability or their estimation via modelling is a general problem that significantly affects the ESSs mapping and benefits estimation. As mentioned in introductory part, understanding, mapping and evaluation of benefits from ecosystems is considered as the first step to enhance their protection, which implies their consideration in the implementation of relevant policies. One of these policies is also water policy, incorporated in the Water Framework Directive.

In principle, achievement of WFD environmental objectives has positive impact on the preservation of habitats and biodiversity. Eventual improvement in the status of waters is the goal of the European Union's current policy; however, the term 'ecosystem services' is not defined in WFD. So many documents (e.g. COWI et al., 2014a,b; Vlachpoulou et al., 2014; Grizzetti et al., 2015a; Grizzetti et al., 2016) try to identify the incorporation of ESSs assessment into water policy. For example, ESSs assessment can be used for potential application of derogations under Article 4 of the WFD, selecting cost-effective measures (Article. 11 WFD) and also designing of measures beyond legislative requirements and limits within payments for ESSs. The evaluation of benefits resulting from the ESSs of inland waters or benefits that are lost when necessary measures are not implemented (and good status of wa- 
ters is not reached) is one of the ways for the estimation of external costs of environmental damage - environmental costs and resource costs what follows from Article 9 of the WFD (Brouwer, 2004). These costs can/should be taken into account for the application of WFD cost recovery principle. Before that, however, it is necessary to have a picture of the capacity of the environment (supply) as well as the effect of the good status of waters or water quality parameters on individual ESSs. Another problem is disaggregation of capacities of individual ESS into water bodies through modelling because there are no direct data. As introduced by Keeler et al. (2012), the use of water and landscape affects water quality and subsequently the capacity of services of water and aquatic ecosystems. As the relation between the change in load environment and changes in service capacity of water and aquatic ecosystems is hardly predictable, the proposal of measures related to the improvement of ecosystem services seems quite problematic. Seifert-Dähnn et al. (2015) pointed to several shortcomings in the use of ecosystem services approach in the implementation of the WFD. Challenges include both methodological (namely, selection of proper valuation method, proper consideration of the trade-offs and side effects) and practical parts. Not insignificant is also the fact that existing evaluation is often very diverse and quite time consuming especially with regard to data acquisition from different sources. Moreover, practical use of ESSs valuation presupposes the use of models that should allow to consider trade-offs and side effects of specific measures.

As published earlier (Bujnovský, 2015) and in previous text, achievement or failure of good ecological status of waters does not always correspond with the provision of ecosystem services. Ecological status of waters is often considered as an expression of the quality of structure and functions (and consequently services) related to aquatic ecosystems that are linked to surface water. As some services of water and aquatic ecosystems are not linked to the achievement of good ecological/chemical status, this fact (in previous sentence) has a relative validity. In addition, some types of water use have designed specific and different qualitative objectives (e.g. surface water for drinking purposes, water for crop irrigation, etc.). Therefore, direct comparison of the value of the lost ESSs with the costs of the measure(s) to reach a good ecological status could be misleading.

Consideration of indicators for evaluating the specific ESSs does not always reflect the nature/principle on which ecosystem is based. For example, indicators such as 'trophic status', 'ecological status' and 'treated wastewater' do not correspond at all with self-cleaning ability of water. Mentioned problem is also reminded by Maes et al. (2016) who say that the fundamental problem of a complete assessment of the ESSs are insufficient data, leading to the use of such indicators which rather reflect pressures on ecosystems than the contribution of ecosystems to regulation and maintenance.

Economic assessment of ecosystem services raises much discussion regarding their potential commodification (e.g. Gómez-Baggethun, Ruiz Pérez, 2011). As Hahn et al. (2015) introduced, demonstrating the value of nature in the financial terms brings the aspect of comparability or interchangeability. This may also be the basis for determining the fees or subsidies for the improvement of ecosystems and related services, although in many cases payments for improvement of ecosystem services are compensations for loss of profit. According to Seifert-Dähnn et al. (2015), biophysical and subsequently monetary valuation can serve as the base for eliciting the importance of individual services. 
Not insignificant is even the fact that the financial statements on ESSs values call for the integration of these values into reporting systems and national accounting (e.g. Hahn et al., 2015; La Note et al., 2017), which potentially may affect the tax burden on population in the future.

At the present time, the significance of the ESSs evaluation may rather lie in the awareness of the value that human society gains from the use of inland waters. According to Schröter et al. (2014), the economic evaluation provides additional information to support decision making but does not replace ethical, environmental or other non-monetary arguments.

It appears that increase in environmental awareness alone is not sufficient in terms of the protection of ecosystems and their services. As stated by OECD (2017), solving of environmental problems requires behavioural changes in human.

As stated by Bujnovský and Vilček (2011), to achieve unambiguous and lasting improvement in this area, it is necessary to address deeper causes, closely related to human thinking and activities. Without thorough knowledge of the real problems, we still solve only symptoms and not the roots. One of the basic reasons of existing environmental problems lies in growing consumption. Instead of meeting the needs, people are trying to satisfy their desires, which are infinite.

There exist more societal forces and phenomena that directly or indirectly affect state and evolution of the environment, and so they become politically significant. Besides economic, political, social and cultural factors, market, advertising, demographic factors and technical developments, it is necessary to mention human convictions, beliefs, values, attitudes and behaviours at the level of individuals, households, communities and whole public (Bechtel and Churchman, 2002; Stern, 2000). Attitudes and behaviours with regard to environment are often reflected in relevant emotions (De Miranda Coelho et al., 2016). People like to overstate the problems or some likes to underestimate. So subjective perceiving of environmental problems together with emotions cannot replace a thorough understanding of the causes of environmental problems and their real solutions. The post-truth world, appealing on emotions, is the real evidence of that.

\section{Conclusion}

The primary aim of the article is to obtain an overview of benefits from actually used inland water ESSs in Slovakia. The evaluation of both surface and ground waters (where relevant) is based on CICES v. 4.3 classification and is primarily focused on demand side, which indicates their actual use. The assessment of water use suitability for a particular purpose (representing a specific ESS) is based on the assumption that the water quality complies with the relevant requirements what is actual in the case of ESSs relevant to water quality.

The evaluation is performed at the level of 10 sub-basins. In the absence of data, the benefit from the use of some ESSs is estimated at the level of whole territory of Slovakia. This is preceded by the choice of economic assessment methods (mainly non-preferential ones) and the corresponding biophysical assessment.

The use of ESSs valuation in practice, especially with regard to water protection of surface water and groundwater, is discussed. Ecological status (ES) of waters is often considered as 
an expression of the quality of structure and functions (and consequently services) related to aquatic ecosystems that are linked to surface water. As some services of water and aquatic ecosystems are not linked to the achievement of good ecological/chemical status, this fact has a relative validity. In addition, some types of water use have designed specific and different qualitative objectives (e.g. surface water for drinking purposes, water for crop irrigation, etc.).

The evaluation of the benefits from ESSs of inland waters in Slovakia so far does not allow direct use of obtained results for proposal of measures within river basin management plans as suggested by several authors. The main reason is the input data availability and quality.

At the present time, the significance of the ESSs evaluation may rather lie in the awareness of the value that human society gains from the use of inland waters. It becomes more evident that increase in environmental awareness alone is not sufficient in terms of the protection of ecosystems and their services. To achieve unambiguous and lasting improvement in this area, it is necessary to address deeper causes, closely related to human thinking and behaviour.

\section{References}

Austin, D., Cerman, G., Heywood, T., Marshall, R., Refling, K. \& Van Patter L. (2012). Valuing natural capital and ecosystem services. Ontario: University of Guelph.

Bechtel, R.B. \& Churchman A. (Eds.) (2002). Handbook of environmental psychology. New York: J. Wiley \& Sons, Inc.

Boyd, J. \& Banzhaf S. (2007). What are ecosystem services? The need for standardized environmental accounting units. Ecological Economics, 63, 616-626. DOI: 10.1016/j.ecolecon.2007.01.002.

Brouwer, R. (2004). The concept of environmental and resource costs. Lessons learned from ECO2. In R. Brouwer \& P. Strosser (Eds.), Environmental and resource costs and the Water Framework Directive. An overview of European practices (pp. 3-12). Workshop Proc. RIZA, Lelystad.

Brouwer, R. (2008). The potential role of stated preference methods in the water framework directive to assess disproportionate costs. Journal of Environmental Planning and Management, 51(5), 597-614. DOI: $10.1080 / 09640560802207860$.

Bujnovský, R. (2015). Evaluation the ecosystem services of inland waters in the Slovak Republic - to date findings. Ekológia (Bratislava), 34(1), 19-25. DOI: 10.1515/eko-2015-0003.

Bujnovský, R. \& Vilček J. (2011). Soil degradation and soil value in Slovakia - Two problems with common denominator. Agriculturae Conspectus Scientificus, 76(1), 9-14.

Burkhard, B., Kroll, F., Nedkov, S. \& Müller F. (2012). Mapping ecosystem service supply, demand and budgets. Ecological Indicators, 21, 17-29. DOI: 10.1016/j.ecolind.2011.06.019.

Cooper, N., Brady, E., Steen, H. \& Bryce R. (2016). Aesthetic and spiritual values of ecosystems: Recognising the ontological and axiological plurality of cultural ecosystem services. Ecosystem Services, 21, 218-229. DOI: 10.1016/j.ecoser.2016.07.014.

COWI (2014a). Support policy development for integration of an ecosystem services approach with WFD and FD implementation. Resource document. Kongens Lyngby: COWI A/S.

COWI (2014b). Support policy development for integration of an ecosystem services approach with WFD and FD implementation. Resource document - Annex report. Kongens Lyngby: COWI A/S.

DeGroot, R., Alkemade, R., Braat, L., Hein, L. \& Willemen L. (2010). Challenges in integrating the concept of ecosystem services and values in landscape planning, management and decision making. Ecological Complexity, 7, 260-272. DOI: 10.1016/j.ecocom.2009.10.006.

DeGroot, R., Brander, L., Van der Ploeg, S., Constanza, R., Bernard, F., Braat, L., Christie, M., Crossman, N., Ghermandi, A., Hein, L., Hussain, S., Kumar, P., McVittie, A., Portela, R., Rodriguez, L.C., ten Brink, P. \& Van Beukering P. (2012). Global estimates of the value of ecosystems and their services. Ecosystem Services, 1, 50-61. DOI: 10.1016/j.ecoser.2012.07.005.

De Miranda Coelha, J.-A.P., Gouveira, V.V., de Souza, G.H.S., Milfont, T.L. \& Barros B.N.R (2016). Emotions toward water consumption: Conservation and wastage. Revista Latinoamericana de Psicología, 48, 117-126. DOI: 10.1016/j.rlp.2015.09.006. 
EEA (2015). The European environment - state and outlook 2015: synthesis report. Copenhagen: European Environment Agency.

Elsin, Y.K., Kramer, R.A. \& Jenkins W.A. (2010). Valuing drinking water provision as an ecosystem service in the Neuse river basin. Journal of Water Research, Planning and Management, 136, 474-482. DOI: 10.1061/(ASCE) WR.1943-5452.0000058

Farber, S., Constanza, R., Childers, D.L., Erickson, J., Gross, K., Grove, M., Hopkinson, Ch.S., Kahn, J., Pincetl, S., Troy, A., Warren, P. \& Wilson M. (2006). Linking ecology and economics for ecosystem management. BioScience, 56(2), 121-133. DOI:10.1641/0006-3568(2006)056[0121:LEAEFE]2.0.CO;2

Gomez-Baggethun, E. \& Ruiz Pérez M. (2011). Economic valuation and the commodification of ecosystem services. Progress in Physical Geography, 35, 613-628. DOI: 10.1177/0309133311421708.

Grizzetti, B., Lanzanova, D., Liquete, C., Reynauld, A., Rankinen, K., Hellsten, S., Forsius, M. \& Cardoso A.C. (2015a). Cook-book for water ecosystem service assessment and valuation. JRC science and policy report. Ispra: JRC.

Grizzetti, B., Passy, P., Billen, G., Bouraoui, F., Garnier, J. \& Lassaletta L. (2015b). The role of water nitrogen retention in integrated nutrient management: assessment in a large basin using different modelling approaches. Environmental Research Letters, 10, 065008.

Grizzetti, B., Lanzanova, D., Liquete, C., Reynaud, A. \& Cardoso A.C. (2016). Assessing water ecosystem services for water resource management. Environmental Science and Policy, 61, 194-203. DOI: 10.1016/j.envsci.2016.04.008.

Grossmann, M. (2012). Economic value of the nutrient retention function of restored floodplain wetlands in the Elbe river basin. Ecological Economics, 83, 108-117. DOI: 10.1016/j.ecolecon.2012.03.008

Gunkel, G., Lima, D., Selge, F., Sobral, M. \& Calado S. (2015). Aquatic ecosystem services of reservoirs in semiarid areas: sustainability and reservoir management. In WIT Transactions on Ecology and The Environment (River Basin Management VIII), 197, 187-200.

Hahn, T., McDermott, C., Ituarte-Lima, C., Schultz, M., Green, T. \& Tuvendal M. (2015). Purposes and degrees of commodification: Economic instruments for biodiversity and ecosystem services need not rely on markets or monetary valuation. Ecosystem Services, 16, 74-82. DOI: 10.1016/j.ecoser.2015.10.012.

Haines-Young, R. \& Potschin M. (2013). CICES V4.3 - Revised report prepared following consultation on CICES Version 4. EEA Framework Contract No EEA/IEA/09/003. University of Nottingham: Centre for Environmental Management.

Chee, Y.E. 2004. An ecological perspective on the valuation of ecosystem services. Biol. Conserv., 120, 549-565. DOI: 10.1016/j.biocon.2004.03.028.

Keeler, B.L., Polasky, S., Brauman, K., Johnson, K.A., Finlay, J.C., O’Neil, A., Kovacs, K. \& Danzell B. (2012). Linking water quality and well-being for improved assessment and valuation of ecosystem services. Pro. Natl. Acad. Sci. USA, 109(45), 18619-18624. https://www.jstor.org/stable/41829961

La Note, A., Maes, J., Grizzetti, B., Bouraoui, F. \& Zulian G. (2012). Spatially explicit monetary valuation of water purification services in the Mediterranean bio-physical region. International Journal of Biodiversity Science, Ecosystem Services and Management, 8(1-2), 26-34. DOI: 10.1080/21513732.2011.645557

La Note, A., Maes, J., Dalmazzone, S., Crossman, N.D., Grizzetti, B. \& Bidoglio G. (2017). Physical and monetary ecosystem service accounts for Europe: A case study for in-stream nitrogen retention. Ecosystem Services, 23 , 18-29. DOI: 10.1016/j.ecoser.2016.11.002.

Maes, J., Braat, L., Jax, K., Hutchins, M., Furman, E., Termansen, M., Luque, S., Paracchini, M.L., Chauvin, Ch., Williams, R., Volk, M., Lautenbach, S., Kopperoinen, L., Schelhaas, M.-J., Weinert, J., Goossen, M., Dumont, E., Strauch, M., Görg, Ch., Dormann, C., Katwinkel, M., Zulian, G., Varjopuro, R., Ratamäki, O., Hauck, J., Forsius, M., Hengeveld, G., Perez-Soba, M., Bouraoui, F., Scholz, M., Schulz-Zunkel, Ch., Lepistö, A., Polishchuk, Y. \& Bidoglio G. (2011). A spatial assessment of ecosystem services in Europe: methods, case studies and policy analysis - phase 1. PEER Report No 3. Ispra: Partnership for European Environmental Research.

Maes, J., Liquete, C., Teller, A., Erhard, M., Paracchini, L.M., Barredo, J.I., Grizzetti, B., Cardoso, A., Somma, F., Petersen, J.E., Meiner, A., Gelabert, E.R., Zal, N., Kristensen, P., Bastrup-Birk, A., Biala, K., Piroddi, Ch., Egoh, B., Degeorges, P., Fiorina, Ch., Santos-Martín, F., Naruševičius, V., Verboven, J., Pereira, H.M., Bengsson, J., Gocheva, K., Marta-Pedroso, C., Snäll, T., Estreguil, Ch., San-Miguewl-Ayanz, J., Péres-Soba, M., GrêtRegamey, A., Lillebø, A.I., Malak, D.A., Condré, S., Moen, J., Czúcz, B., Drakou, E.G., Zulian, G. \& Lavalle C. (2016). An indicator framework for assessing ecosystem services in support of the EU Biodiversity Strategy to 2020. Ecosystem Services, 17, 14-23. DOI: 10.1016/j.ecoser.2015.10.023. 
Millennium Ecosystem Assessment (2005). Ecosystems and human well-being: Synthesis. Washington, DC: Island Press.

Ministry of Agriculture and Rural Development (MoA \& RD) (2013). Multiannual National Strategic Plan for the Development of Aquaculture of the Slovak Republic for period 2014-2020 (in Slovak). Bratislava: Ministry of Agriculture and Rural Development.

Ministry of Environment (2011). Concept of utilization of hydropower potential of watercourses of the Slovak Republic by 2030 (in Slovak). Bratislava: Ministry of Environment.

Morris, J. \& Camino M. (2011). Economic assessment of freshwater, wetland and floodplain (FWF) ecosystem services. UK NEA Economics analysis report. Bedford: School of Applied Sciences, Cranfield University.

Morvay, K., Frank, K., Gabrielová, H., Hudcovský, M., Hvozdíková, V., Jeck, T. \& Šikulová I. (2014). Economic development of Slovakia in 2013 and outlook to 2015 (in Slovak). Bratislava: Ekonomický ústav SAV.

National Centre for Groundwater Research and Training (NCGRT) (2013). Economic value of groundwater in Australia. Kingston : Deloitte Access Economics.

OECD (2017). Tackling environmental problems with the help of behavioural insights. Paris: OECD Publishing.

Rode, M., Hartwig, M., Wagenschein, D., Kebede, T. \& Borchardt D. (2015). The importance of hyporheic zone processes on ecological functioning and solute transport of streams and rivers. In L. Chicharo, F. Müller \& N. Fohrer (Eds.), Ecosystem services and river basin ecohydrology. Dordrecht: Springer Science + Media B.V.

Rohani, M. (2013). Freshwater values framework. A review of water valuation methods utilized within total economic valuation. Auckland Council working report WR2013/001. Auckland: Auckland Council.

Seifert-Dähnn, I., Barkved, L.J. \& Interwies E. (2015). Implementation of the ecosystem service concept in water management - Challenges and ways forward. Sustainability of Water Quality and Ecology, 5, 3-8. DOI: 10.1016/j.swaqe.2015.01.007.

Seitzinger, S., Harrison, J.A., Böhlke, J.K., Bouwman, A.F., Lowrance, R., Peterson, B., Tobias, C. \& van Drecht, G. (2006). Denitrification across landscapes and waterscapes: a synthesis. Ecol. Appl., 16(6), 2064-2090. DOI: 10.1890/1051-0761(2006)016[2064:DALAWA]2.0.CO;2

Seják, J., Cudlín, P., Pokorný, J., Zapletal, M., Petřŕček, V., Guth, J., Chuman, T., Romportl, D., Skořepová, I., Vacek, V., Vyskot, I., Černý, K., Hesslerová, P., Burešová, R., Prokopová, M., Plch, R., Engstová, B. \& Stará L. (2010). Evaluation of ecosystem functions and services in Czech Republic (in Czech). Ústí nad Labem: Fakulta životního prostředí UJEP.

Schröter, M., Van der Zanden, E., Van Oudenhoven, A.P.E., Remme, R.P., Serna-Chavez, H.M., de Groot, R.S. \& Opdam P. (2014). Ecosystem services as a contested concept: A synthesis of critique and counter-arguments. Conservation Letters, 7(6), 514-523. DOI: 10.1111/conl.12091.

Stern P.C. (2000). Psychology and the science of human-environment interactions. American Psychologist, 55, 523-530. DOI: 10.1037/0003-066X.55.5.523.

Vlachopoulou, M., Coughlin, D., Forrow, D., Kirk, S., Logan, P. \& Voulvoulis N. (2014). The potential of using the ecosystem approach in the implementation of the EU Water Framework Directive. Sci. Total Environ., 470-471, 684-694. DOI: 10.1016/j.scitotenv.2013.09.072.

Ward, F.A. \& Michelsen A. (2002). The economic value of water in agriculture: concepts and policy applications. Water Policy, 4, 423-446.

Wollheim, W.M., Vörösmarty, C.J., Peterson, B.J., Seitzinger, S.P. \& Hopkinson C.S. (2006). Relationship between river size and nutrient removal. Geophysical Research Letters, 33, L06410. DOI: 10.1029/2006GL025845.

WWAP - United Nations World Water Assessment Programme (2014). The United Nations World Water Development Report 2014. Water and energy. Paris: UNESCO. 